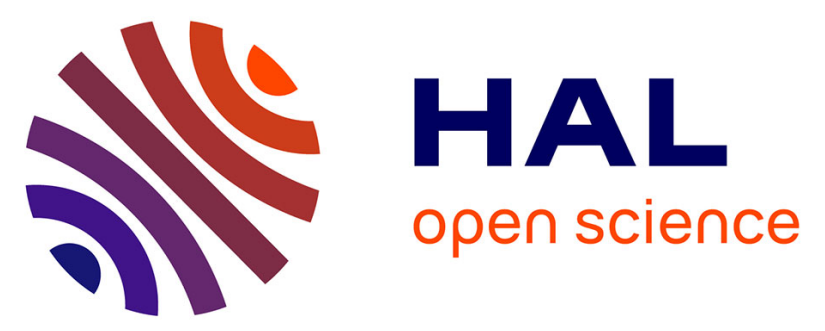

\title{
Glass transition temperatures of isotactic poly(methymethacrylate) thin films and individual chains probed by multi wavelength ellipsometry
}

A. El Ouakili, G. Vignaud, E. Balnois, Jean-François Bardeau, Y. Grohens

\section{- To cite this version:}

A. El Ouakili, G. Vignaud, E. Balnois, Jean-François Bardeau, Y. Grohens. Glass transition temperatures of isotactic poly(methymethacrylate) thin films and individual chains probed by multi wavelength ellipsometry. European Physical Journal: Applied Physics, 2011, 56 (1), pp.13703. 10.1051/epjap/2010100221 . hal-00736285

\section{HAL Id: hal-00736285 \\ https://hal.science/hal-00736285}

Submitted on 28 Sep 2012

HAL is a multi-disciplinary open access archive for the deposit and dissemination of scientific research documents, whether they are published or not. The documents may come from teaching and research institutions in France or abroad, or from public or private research centers.
L'archive ouverte pluridisciplinaire HAL, est destinée au dépôt et à la diffusion de documents scientifiques de niveau recherche, publiés ou non, émanant des établissements d'enseignement et de recherche français ou étrangers, des laboratoires publics ou privés. 


\title{
Glass transition temperatures of isotactic
}

\section{poly(methymethacrylate) thin films and individual chains probed by multi wavelength ellipsometry}

\author{
Abderrahim El Ouakili ${ }^{\text {a,b }}$ - Guillaume Vignaud ${ }^{b^{*}}-$ Eric Balnois ${ }^{b}-$ Jean- \\ François Bardeau ${ }^{\text {a }}$-Yves Grohens ${ }^{\text {b }}$ \\ ${ }^{a}$ Laboratoire de Physique de l'Etat Condensé UMR CNRS 6087, Université du Maine, \\ Avenue Olivier Messiaen, 72085 Le Mans Cedex 9, France \\ ${ }^{b}$ Laboratoire d'Ingénierie des Matériaux de Bretagne (LIMATB), Université de \\ Bretagne Sud (UEB), Centre de Recherche, BP 92116, Rue Saint Maudé, 56321 \\ Lorient, France
}

ABSTRACT. Ellipsometry is used as a technique to determine glass temperature transitions of isotactic Poly(methyl methacrylate) (iPMMA) ultra-thin films and isolated chains deposited on a silicon wafer surface. The importance of systematically probing the samples at different wavelengths is pointed out in this work since for a similar thin film, slope changes in delta are more or less pronounced according to the wavelength used. The technique performed on iPMMA thin films and isolated globular chains, deposited on Piranha treated surfaces, reveals the presence of multiple transitions, whereas films of comparable thicknesses deposited on HF treated silicon wafers show 
only one transition. The results confirm the assumptions of a layered structure yielding specific $T g(h)$ which depends on depth location, which is in good agreement with recent theories of glass transitions in confined polymers, and emphasize the influence of polymer-substrate interactions and chain disentanglement.

KEYWORDS: glass transition, thin film, layered structure, ellipsometry, PS, PMMA, iPMMA, isolated chain 


\section{Introduction}

The glass transition of polymer thin films has been the subject of numerous works published over a decade [1-3]. Keddie et al. [1] were the first to point out glass transition temperature (Tg) deviation by ellipsometry for Poly(methyl methacrylate) (PMMA) thin films with thicknesses below $50 \mathrm{~nm}$. Other techniques have been used to better understand this phenomenon, such as Brillouin scattering [4], dielectric spectroscopy [5-11], and X-ray reflectivity [12-14]. Through these experiments, polymer film $\mathrm{T}_{\mathrm{g}}$ was shown to increase in the case of strong interaction with the substrate and decrease in the case of weak interaction $[1,13,15]$.

More recently, through fluorescence relaxation studies, Torkelson et al. [16-24], and Tanaka et al. [25], demonstrated that $\mathrm{T}_{\mathrm{g}}$ depends on the location of fluorescent probes in the film. The glass transition temperature can vary by $30{ }^{\circ} \mathrm{C}$ when chromophores are located near one of the interfaces. The idea of a thin film having only a single $\mathrm{Tg}$ has been refuted by these experiments. Raman microspectrometry [26] also revealed the presence of two glass transitions on isotactic PMMA (iPMMA) films on silicon oxide surfaces. The first transition was associated with the existence of a middle layer in which $\mathrm{Tg}$ is identical to the bulk material $\left(60^{\circ} \mathrm{C}\right)$. The second transition was interpreted as the consequence of polymer-substrate interactions and was shown to be influenced by the initial solution concentration, which itself can play a role on the conformation and orientation of polymer chains on the surface $[12,27]$.

Glass transition measurements in polymer thin films through mono-wavelength 
ellipsometry in the dynamic mode have almost always revealed only one $\operatorname{Tg}[1,2,4,15$, 28-33]. Only Kawana et al. [34] and more recently Kim et al. [35] using ellipsometry on PS thin films pointed out a broadening of the glass transition region. These authors interpreted this broadening effect as the possible presence of two different glass transition temperatures, respectively denoted $\mathrm{T}$ - and $\mathrm{T}+$. The evolution of $\mathrm{T}+$ and $\mathrm{T}-$ temperatures as a function of the film thickness could be linked to the presence of different layers with different mobility in the film. The polymer chains in the surface layer show an increase of mobility while the chains near the substrate show a decrease of mobility due to possible interactions and reconformation. This layer model was initially presented by DeMaggio et al. [36] and experimentally validated by Ellison and Torkelson [17].

In the present work, the wavelength of the incident beam of the ellipsometer was varied in order to enhance the sensitivity of the technique to detect multiple glass transition temperatures, if any, in iPMMA thin films and follow their trend when the film is confined to isolated iPMMA chains on a substrate. In addition, the effect of polymer-surface interactions on the modification of $\operatorname{Tg}(\mathrm{h})$ will be studied by tuning the chemistry of the silicon wafer surface.

\section{Experimental methods}

Polymer thin films of different thicknesses were prepared by spin coating different concentrations of isotactic PMMA solutions $(\mathrm{Mw}=150 \mathrm{Kg} / \mathrm{mol}, \mathrm{I}=1.10$ for the iPMMA, from Polymer Source) on silicon wafers (100). Chloroform was used as a 
solvent to dissolve iPMMA. Silicon wafers have a very thin layer of silicon oxide $(15 \AA$ as measured by ellipsometry) formed on the surface of the crystalline silicon. These substrates underwent two different chemical treatments, Hydrofluoric acid (HF) and Piranha [37], to influence the interaction between the polymer and substrate surface. The piranha treatment consists in inserting the silicon wafer surface in a 3:1 mixture of sulfuric acid and $30 \%$ hydrogen peroxide at $80{ }^{\circ} \mathrm{C}$ for 30 minutes to remove any organic residues or contamination from the substrate. After the treatment, the surfaces are extensively rinsed with deionised water and dried under filtered nitrogen. To avoid any contamination, the polymer solution is directly spin-coated on the surface. The HF treatment consists in putting the substrate in a $\mathrm{HF}$ acid solution (5\% in volume) for 5 minutes before rinsing and drying the surface as above. The chemical treatment efficiency on the quality of the substrate surface was controlled by contact angle measurement. The polar components of surface energies inferred from the Owens and Wendt [38] model are, respectively, $43 \mathrm{~mJ} / \mathrm{m}^{2}$ and $7 \mathrm{~mJ} / \mathrm{m}^{2}$ for treated Piranha and HF surfaces respectively. These measures validate the roles played by both treatments, on the one hand the removing of the oxide layer by the HF treatment which yields an hydrophobic substrate and on the other hand, the activation of silanol groups $(\mathrm{Si}-\mathrm{OH})$ on the substrate following the Piranha treatment to yield a polar and hydrophilic substrate.

Besides thin films, isolated polymer chains or globular entities, shown in Figure 5, were prepared from highly diluted solutions of iPMMA cast on Piranha treated Si substrate silicon. Before analysis, thin films and globular entities were dried and 
annealed in vacuum, at $150{ }^{\circ} \mathrm{C}$ for $24 \mathrm{~h}[1,19,21,22,26,29,33-36]$. The aim of this treatment is to remove most of the residual solvent within the film and to relax constraints induced by the spin coating process. The thicknesses of the annealed films were measured between 5 and $200 \mathrm{~nm}$ by ellipsometry and AFM. AFM images also revealed that the films were homogeneous and extremely flat with typical roughness (root mean square) of the order of $4 \AA$ on a large area $\left(100 \mu \mathrm{m}^{2}\right)$. For non complete films, globular entities were observed by AFM which is typical of flexible polymer chains. The sizes of these globules present on the silicon wafer surface were measured from the AFM images by using the section analysis software (Nanoscope software, v6.13) on at least 200 different entities, either present on different areas of a sample or on different similar samples.

Spectroscopic ellipsometry was used as a measuring technique to detect thermal variation $\left(30\right.$ to $150{ }^{\circ} \mathrm{C}$ ) and transitions in iPMMA samples. The Jobin Yvon - Uvisel instrument equipped with a hot stage is mainly composed of a Xenon source ranging from long-range infrared to ultraviolet $(250-1700 \mathrm{~nm})$, a polarizer, an analyser, and a monochromator handling the dispersion and the selection of the wavelength to a photomultiplier. The measurements were all taken under ambient conditions (55\% of relative humidity). The reproducibility of the measurements was confirmed by performing at least three $\Delta$ measurements in different areas of a same sample. No significant change in its behaviour could be detected, thus implying that there will be no observable degradation of the heated polymer under ambient conditions within the range of temperature studied here, in accordance with the recent studies of Raegen et al. 


\section{Results and discussions}

\subsection{Sensitivy of ellipsometric measurements to the energy of the incident light beam}

In the literature, for $\mathrm{Tg}$ measurements, ellipsometry is generally operated at a fixed energy or wavelength. Although the method was shown to be suitable to detect transitions in polymer thin film, we think that improving its sensitivity may be useful to detect less visible transitions in a film, which would forward for a complementary or more precise description of the properties of confined polymer films, as has been recently observed though other techniques [e.g. 16-24]. Thus, around fifteen different energies ranging between $1.6 \mathrm{eV}$ and $4.5 \mathrm{eV}$ were used to measure $\Delta(\mathrm{T})$ every $5{ }^{\circ} \mathrm{C}$ for each film in this study. The objective is to improve the ellipsometry measurement sensitivity to any change in indices or film thickness. Figure 1 represents the variation of $\Delta$ for a $100 \mathrm{~nm}$ thick iPMMA film deposited on silicon wafer with a Piranha treatment as a function of the temperature. It can be observed that slope changes are more or less pronounced depending on the energy used. For example, the break in the slope is more pronounced at $4 \mathrm{eV}$ than at $1.5 \mathrm{eV}$, which indicates that for this particular type of sample, observed at an incident angle of $70^{\circ}$, the best energy to detect transition from changes in the $\Delta$ parameter will be $4 \mathrm{eV}$. For our study, we chose to represent $\Delta$ rather than $\psi$ as a function of temperature because the analysis of all our measurements 
reveals that $\Delta(\lambda)$ is about eight times more sensitive than $\psi(\lambda)$. During the reflection of the incident beam, the polarization of the electric field measured by $\Delta$ is possibly influenced more by small changes in optical properties of the film than the amplitude of the field on which $\psi$ depends.

At this stage, an intriguing question is, how can we explain the differences between the breaks in the slope observed at Tg according to the energy used as shown in Figure 1?

If a thin, transparent film covers a substrate, Drude has shown that the measured value of $\Delta$ is a function of both the thickness, $\mathrm{d}$, and the refractive index, $\mathrm{n}$, of the thin film [39]. As reported by Drude, the reflected delta is given by:

$$
\Delta=\Delta_{\mathrm{s}}+\mathrm{K} \frac{4 \pi \mathrm{d}}{\lambda} \frac{\mathrm{n}^{2}(\lambda)-1}{\mathrm{n}^{2}(\lambda)}
$$

where $\mathrm{K}$ is a constant. The refractive index of the film depends on the wavelength of the incident light $\lambda$. The first term of the equation, $\Delta_{s}$, is the ellipsometric angle reflected by the substrate. The second term describes how the film influences $\Delta$. While the film is being heated, the ellipsometric angle, $\Delta$, linearly evolves as a function of the temperature as can be seen in Figures 1,3 and 6 for instance. At the glass transition temperature, the modification of the thickness and the refractive index yield a kink in the recorded signal, leading to a slope change. Then, if these changes in the refractive index and the thickness are dependant on the wavelength used, this can lead to a more or less important impact on the change of slope of the measured $\Delta$. 
Another possible cause of this energy-dependent sensitivity comes from the reflected signal by the substrate, represented by $\Delta_{\mathrm{s}}$ in equation (1). At a fixed energy, the ellipsometric angle $\Delta_{\mathrm{s}}$ of the substrate is "incident angle" dependant, as can been seen in Figure 2. The relation between the incident angle on the surface $\theta_{0}$, (i.e. at the airpolymer interface), the incident angle at the polymer-substrate interface $\theta_{1}$ and the refractive index of the film is given by Snell's law:

$$
\sin \left(\theta_{0}\right)=n(\lambda) \sin \left(\theta_{1}\right)
$$

This law shows that a variation of refractive index $n(\lambda)$ of the film, for a fixed $\theta_{0}$, will modify the incidence angle $\theta_{1}$ and consequently will lead to a change in $\Delta_{\mathrm{s}}$. Any change in the refractive index of the film will thus lead to a variation of $\Delta$ measured. Moreover, for a variation $\delta \theta_{1}$ of the incident angle, the corresponding change $\delta \Delta_{\mathrm{s}}$ depends on the energy of the incident beam. For example, when $\theta_{1}=75^{\circ}, \Delta_{\mathrm{s}}\left(\theta_{1}\right)$ goes abruptly from 180 to $0^{\circ}$ at $2 \mathrm{eV}$ while its decrease is more gradual, and around $35^{\circ}$ at $4 \mathrm{eV}$ (Figure 2). The sensitivity of the technique seems to be conditioned by $\mathrm{d} \Delta_{\mathrm{S}} / \mathrm{d} \theta_{1}$ for a given energy. Figure 2 also underlines the importance of the incident angle in the variation of $\delta \Delta$. For the study of a PMMA film, for instance, if the incident angle at the air-polymer interface is $\theta_{0}=70^{\circ}$, the refracted beam will reach the silicon wafer at an angle of about $\theta_{1}=40^{\circ}$. The variation in $\delta \Delta_{\mathrm{s}}$ is negligible at $2 \mathrm{eV}$, whereas it is approximatively $10^{\circ}$ at $4 \mathrm{eV}$. For that incident angle, energy of $4 \mathrm{eV}$ will be more sensitive to measure $\delta \Delta$ changes in a polymer thin film. On the contrary, for the study of isolated chains deposited on oxide silicon surfaces the most sensitive energies are in the infrared range. 
In this case, owing to the few polymer chains deposited on substrate, the incident beam, with an angle of $75^{\circ}$, will be only slightly deviated towards $70^{\circ}$ leading to a significant deviation of $\Delta_{\mathrm{s}}$. The choice of $\theta_{0}$ is thus a fundamental parameter of the technique that needs to be optimised in correlation with the choice of the energy. Both parameters are, of course, linked, as discussed above.

Even though all measurements, performed on different film thicknesses, show energy dependence, the possibility of theoretically predicting the most sensitive energy still remains highly complicated. Several factors must be taken into account, such as:

- the non-homogeneity, if any, of the refraction index in the film thickness. This is particularly true in the case of polymer-substrate interaction or in the presence of a liquid layer on the surface that would generate a non-uniform atomic density within the film.

- $\quad$ the link between energy, temperature, and refraction index of the film. Does the refractive index evolution as a function of temperature depend on energy?

- $\quad$ the refractive index evolution of substrate as a function of temperature...

A quantitative and predictive simulation requires in-depth knowledge of all these physical parameters for the studied system, such as the atomic density profile within the film. No model of this kind is currently available, nonetheless, there are currently numerous benefits in experimentally observing the evolution of $\Delta$ as a function of temperature at different incident beam energies to better characterise transitions in thin films. 


\subsection{Application to $\mathrm{Tg}(\mathrm{h})$ measurement iPMMA films and isolated chains}

The ellipsometric signals recorded at two different energies for iPMMA films deposited on Piranha treated Si substrates are shown in Figure 3. For this treatment, the chemical activation of the wafer surface generates the creation of strong interactions with the polymer. The interactions between iPMMA carbonyl groups and silanols of the activated surface are of the acid-base kind, as described in the framework of the Lewis concept [40]. Figure 3a reveals the presence of several slope breaks on the delta curves as a function of $\mathrm{T}$. The multiple glass transitions in thin film can be explained by the existence of a stratification phenomenon in the film, in which every layer possesses a visible Tg. DeMaggio et al. [36] proposed that thin film could be described by a threelayer model with different thermal properties. They associate the lowest $\mathrm{Tg}$ to a substantial layer with an increased mobility over bulk Tg, presumably at the surface of the polymer. Oppositely, a layer with a reduced mobility would be present near the substrate due to strong interaction between the polymer and the substrate. Finally, the intermediate layer will hold a glass transition similar to the bulk $\mathrm{Tg}$.

In the present system, the iPMMA film can be described by a two-layer model (Figure 4), as shown by the presence of two transitions, with a bulk-like middle layer $\mathrm{T} \pm$ and an interacting layer at the polymer-substrate interface $\mathrm{T}+[26,29,36]$. Polymer-substrate attraction can temporarily trap chain segments and cause their dynamic slowness in this layer in comparison to what can be seen in the volume. The second transition, at $55^{\circ}$ is rather constant over the whole range of film thickness and corresponds well to the bulk Tg of PMMA. It can be observed that for increasing film thickness, T+ gradually 
decreases and converges to T+- for a film thickness of around $100 \mathrm{~nm}$ (Figure 4a). Bulk properties of polymer films are indeed generally obtained for a film thickness of, or above, $100 \mathrm{~nm}$. This phenomenon can be explained by the different conformations of interacting polymer chains. For the thinnest film, obtained from diluted solutions, the polymer may adopt an elongated structure parallel to the surface to optimise its number of contacts, corresponding well with the strong adsorption of PMMA with the activated surface and the low number of molecules acting per reacting sites. It is thus likely that the mobility of these chains is reduced proportionally to the numbers of contacts of the chain with the surface. In opposition, for thick films obtained from more concentrated solutions, the competition between the chains and the reacting surface sites can limit the number of contacts and consequently give different chain conformations. This directly affects the mobility of the chains to converge towards T+-.

As previously discussed, the observation of several Tg below this critical thickness would be related to a stratification process occurring in the thin films. According to the three-layer model [36], no mobile layer at the gas-solid interface can be observed here in contrast with PS [3] probably because PMMA is much less sensitive to confinement effects as discussed further in the text.

To illustrate the importance of varying the energy of the incident beam to emphasize the sensitivity of ellipsometry, Figures $3 \mathrm{a}$ and $3 \mathrm{~b}$ show different trends for similar thin films $(22 \mathrm{~nm})$ : On the one hand, at $3.4 \mathrm{eV}$, two transitions can be easily observed whereas, on the other hand, at $2.2 \mathrm{eV}$, although the first transition $\left(55^{\circ}\right)$ is clear, the second is rather uncertain. This underlines the importance of testing different wavelengths in the glass 
temperature determination by ellipsometry.

The results obtained for iPMMA films prepared by spin coating on HF treated silicon wafers reveal the presence of a unique and constant transition, $\mathrm{T} \pm$ no matter the thicknesses (Figure 4b). In this case, all ellipsometric data, recorded at different energies, showed only one transition. From the literature, for PS on an HF treated surface, which is considered as a repulsive surface, confinement effects lead to a $\mathrm{Tg}$ depression for a thickness below $100 \mathrm{~nm}[2,3]$. The different behaviour of iPMMA can be explained by the fact that the polymer is less sensitive to confinement effects than the PS is, as is mentioned by Roth et al. [41]. These authors reported that the overall magnitude of Tg reduction in a free-standing PMMA film is less important (by roughly a factor of three) than that observed in free-standing PS films of comparable molecular weight and thickness. They interpreted their results by suggesting that this difference in Tg reduction is due to differences in the chemical structure of the polymers. It was reported that for PMMA, motions associated with $\alpha$ and $\beta$ relaxations are more complex than for other polymers due to its molecular structure. In particular, energy transfer between the backbone and side groups may occur through side chain rotation and thus energy compensation. These unsual local coupling effects were even found to be more prominent in isotactic PMMA in comparison with syndiotactic PMMA [42]. Our system also presents a $\mathrm{Tg}$ reduction which is less significant than that of i-PMMA free-standing film. This difference can be interpreted by the different nature of interactions between the air-polymer interface which can be seen as a repulsive wall [41] and the polymer substrate interface on which the HF treated surface can lead to few but possible 
interactions. Indeed the interactions tend to slightly increase $\mathrm{Tg}$ whereas confinement effects tend to decrease it.

In order to better understand the importance of interactions and confinement effects on the glass transition, ellipsometric measurements have been performed on isolated polymer chains cast on silicon wafers from highly diluted solutions. The corresponding AFM images of isolated polymer entities are presented in Figure 5. Globules, with typical mean heights of $2.5 \pm 0.5 \mathrm{~nm}$ and mean lateral dimension of $60 \pm 8 \mathrm{~nm}$ are homogeneously distributed on the silicon wafer surface, showing a uniform distribution of the polymer on the surface (Figure 5). On a larger area $(10 \mu \mathrm{m} \times 10 \mu \mathrm{m})$, only very few aggregates, with typical heights of about 6-8 $\mathrm{nm}$ and lateral distances of a few hundred nanometers were found. The experimental AFM volume of the observed globules, assuming a hemispherical geometry, was found to be $4900 \mathrm{~nm}^{3}$. This calculation is simply an approximation since the AFM values can be overestimated due to convolution effects that are known to over-estimate lateral dimensions. From its molar mass, the hydrodynamic volume of the polymer (considering a sphere) can be estimated to be about $4800 \mathrm{~nm}^{3}$ [43]. Thus we can conclude that the observed objects on the surface are presumably isolated and individual macromolecules. In a previous work, Kumaki et al. [44] also observed individual chains of i-PMMA deposited on mica, but the conformation of the polymer was more extended than globular. Such a difference can be explained by the properties of the depositing surface, the deposition conditions and/or the sample annealing treatment.

For such individual entities, deposited on a Piranha treated surface, the results 
shown in Figure 6 demonstrate the ability of multi-energy ellipsometry to detect $\mathrm{Tg}$ on isolated iPMMA chains. The glass transition temperature was up to now principally studied in polymer films rather than individual or isolated entities. However, two groups already postulated the existence of a transition for isolated and individual macromolecules $[45,46]$. It can be recalled here that the $\mathrm{Tg}$ cooperative process involves concerted molecule motions in a cooperative region that is generally spatially extended to 2-3 nm [47]. The radius of gyration of our iPMMA chains (typically $\mathrm{Rg}=$ $10.5 \mathrm{~nm}$ ) is far higher than this cooperative extended length.

The two experimentally measured transition values $\left(57^{\circ} \mathrm{C}\right.$ and $\left.85^{\circ} \mathrm{C}\right)$ can be discussed with the following hypotheses. We may consider that, even if individual macromolecules are well dispersed on the substrate, on a larger area (typically of the same order of magnitude of the footprint of the incident beam on the surface, i.e. 2 $\mathrm{mm}^{2}$ ) some aggregates, but few large ones, can be found. Thus both transitions could be ascribed to, on the one hand, individual macromolecules $\left(85^{\circ} \mathrm{C}\right)$ and on the other hand, to larger aggregates $\left(57^{\circ} \mathrm{C}\right)$. According to the size of the aggregates, chains show a bulk-like behaviour. For individual chains, the mobility is reduced due to their strong interactions with the surface. However, it should be noticed that the $\mathrm{T}+$ transition observed at $85^{\circ} \mathrm{C}$ is lower than the $110^{\circ} \mathrm{C}$ measured for iPMMA thin films. This lower Tg value can be explained by the fact that isolated chains are presumably less entangled than polymer chains in thin films, thus conferring to these entities a higher mobility than entangled polymer chains. The amplitude of the disentanglement and the effect on $\mathrm{Tg}$ reduction, if any [48], is still unclear [49]. Further experiments performed on isolated 
chains by different techniques should, therefore, provide further insight into the physics of polymer chains at surfaces or in confined states.

\section{Conclusion}

Ellipsometry optimized incident beam energy was used in order to gain the maximum amount of sensitivity in determining clear polymer transitions in ultra thin iPMMA films and isolated chains. The Piranha treated surfaces reveal two $\operatorname{Tg}(\mathrm{h})$ which are respectively $\mathrm{T}+$ at the substrate-polymer interface and $\mathrm{T} \pm$ for the other part of the film, as a consequence of a layered structure in the film depth. On the other hand, iPMMA on the HF treated substrates reveals only one $\operatorname{Tg}(\mathrm{h})$ that remains constant with thickness due to a weak sensitivity to confinement effects. For iPMMA isolated chains, known for creating strong interaction on an activated silicon wafer surface, two different $\operatorname{Tg}(\mathrm{h})$ were also determined. The capability of multi wavelength ellipsometry to detect transitions for isolated chains opens up new fields for the study of entanglements of polymer in confined state.

\section{Acknowledgments}

The authors acknowledge the Brittany region, the Pays de la Loire region and the European Community for their financial support. 


\section{References}

[1] J. L. Keddie, R. A. L. Jones, R. A. Cory, Faraday Discuss. 98, 219 (1994).

[2] G. Beaucage, R. Composto, J. Polym. Sci., Part B: Polym. Phys. 31, 319 (1993).

[3] J.A. Forrest, K. Dalnoki-Veress, Adv. Colloid Interface Sci. 94, 167 (2001).

[4] J.A. Forrest, K. Dalnoki-Veress, J.R. Dutcher, Phys. Rev. E. 56, 5705 (1997).

[5] K. Fukao, Y. Miyamoto, Europhys. Lett. 46, 649 (1999).

[6] K. Fukao, Y. Miyamoto, Phys. Rev. E. 61, 1743 (2000).

[7] R.D. Priestley, L.J. Broadbelt, J.M. Torkelson, K. Fukao, Phys. Rev. E. 75, 061806 (2007).

[8] M. Wubbenhorst, C.A. Murray, J.R. Dutcher, Eur. Phys. J. E. 12, S109 (2003).

[9] S. Napolitano, M. Wubbenhorst, J. Phys. Chem. B. 111, 9197 (2007).

[10] S. Peter, S. Napolitano, H. Meyer, M. Wubbenhorst, J. Baschnagel, Macromolecules 41, 7729 (2008).

[11] D. Labahn, R. Mix, A. Schonhals, Phys. Rev. E. 79, 011801 (2009).

[12] J.H. Van Zanten, W.E. Wallace, W.L. Wu, Phys. Rev. E. 53, 2053 (1996).

[13] O.K.C. Tsui, T.P. Russell, C.J. Hawker, Macromolecules 34, 5535 (2001).

[14] T. Miyazaki, K. Nishida, T. Kanaya, Phys. Rev. E. 69, 061803 (2004).

[15] D.S. Fryer, R.D. Peters, E.J. Kim, J.E. Tomaszewski, J.J. de Pablo, P.F. Nealey, C.C. White, W.L. Wu, Macromolecules 34, 5627 (2001). 
[16] C.J. Ellison, S.D. Kim, D.B. Hall, J.M. Torkelson, Eur. Phys. J. E. 8, 155 (2002).

[17] C.J. Ellison, J.M. Torkelson, Nat. Mater. 2, 695 (2003).

[18] C.J. Ellison, R.L. Ruszkowski, N.J. Fredin, J.M. Torkelson, Phys. Rev. Lett. 92, 095702 (2004).

[19] C.J. Ellison, M.K. Mundra, J.M. Torkelson, Macromolecules 38, 1767 (2005).

[20] R.D. Priestley, C.J. Ellison, L.J. Broadbelt, J.M. Torkelson, Science 309, 456 (2005).

[21] M.K. Mundra, C.J. Ellison, R.E. Behling, J.M. Torkelson, Polymer 47, 7747 (2006).

[22] C.B. Roth, J.M. Torkelson, Macromolecules 40, 3328 (2007).

[23] P. Rittigstein, R.D. Priestley, L.J. Broadbelt, J.M. Torkelson, Nat. Mater. 6, 278 (2007).

[24] M.K. Mundra, C.J. Ellison, P. Rittigstein, J.M. Torkelson, Eur. Phys. J. ST 141, 143 (2007).

[25] K. Tanaka, Y. Tateishi, Y. Okada, T. Nagamura, M. Doi, H. Morita, J. Phys. Chem. B. 113, 4571 (2009).

[26] G. Vignaud, J.-F. Bardeau, A. Gibaud, Y. Grohens, Langmuir 21, 8601 (2005).

[27] X. Zheng, M.H. Rafailovich, J. Sokolov, Phys. Rev. Lett. 79, 241 (1997).

[28] O.K.C. Tsui, H.F. Zhang, Macromolecules 34, 9139 (2001).

[29] Y. Grohens, L. Hamon, G. Reiter, A. Soldera, Y. Holl, Eur. Phys. J. E. 8, 217 
(2002).

[30] Z. Fakhraai, J.A. Forrest, Phys. Rev. Lett. 95, 025701 (2005).

[31] C.H. Park, J.H. Kim, M. Ree, B.H. Sohn, J.C. Jung, W.C. Zin, Polymer 45, 4507 (2004).

[32] C.G. Campbell, B.D. Vogt, Polymer 48, 7169 (2007).

[33] A. Raegen, M. Massa, J. Forrest, K. Dalnoki-Veress, Eur. Phys. J. E. 27, 375 (2008).

[34] S. Kawana, R.A.L. Jones, Phys. Rev. E. 63, 021501 (2001).

[35] S. Kim, S.A. Hewlett, C.B. Roth, and J.M. Torkelson, Eur. Phys. J. E. 30, 83 (2009).

[36] G.B. DeMaggio, W.E. Frieze, D.W. Gidley, H.A. Hristov, A.F. Yee, Phys. Rev. Lett. 78, 1524 (1997).

[37] P. Dumas, Y.J. Cwal and P. Jakob, Surf. Sci. 867, 269 (1992).

[38] D.K. Owens, R.C. Wendt, J. Appl. Polym. Sci. 13, 1741 (1969).

[39] Handbook of Ellipsometry edited by H.G. Tompkins, E.A. Irene, (William Andrew Publishing, 2005) p 282.

[40] M.L. Hair, in Colloidal silica: fundamentals and applications edited by H. E. Bergna, W. O. Roberts, (CRC Press, Taylor \& Francis, 2006).

[41] C.B. Roth, A. Pound, S.W. Kamp, C.A. Murray, and J.R. Dutcher, Eur. Phys. J. E 20, 441 (2006). 
[42] Y. Grohens, R.E. Prud'homme, J. Schultz, Macromolecules 31, 2545 (1998).

[43] Eric Balnois, Kevin J. Wilkinson, Jamie R. Lead, and Jacques Buffle, Environ. Sci. Technol., 33 (21), 3911 (1999).

[44] J. Kumaki, T. Kawauchi, E. Yashima, Macromolecules 39, 1209 (2006).

[45] A. Serghei, Macromol. Chem. Phys. 209, 1415 (2008).

[46] A. Narladkar, E. Balnois, G. Vignaud, Y. Grohens, Macromol. Symp., 273, 146, (2008)

[47] E. Donth, H. Huth and M. Beiner, Characteristic length of the glass transition, J Phys: Condens Matter 13, 451 (2001).

[48] H.Itagaki, Y.Nishimura, E.Sagisaka, and Y.Grohens, Langmuir 22, 742 (2006).

[49] Si, M. V. Massa, K. Dalnoki-Veress, H. R. Brown, and R. A. L. Jones, Phys. Rev. Lett. 94, 127801 (2005). 


\section{Figure captions:}

Figure 1. Evolution of $\Delta$ as a function of temperature for a 100 nm-thick iPMMA film measured with an incident angle of $70^{\circ}$.

Figure 2. Theoretical evolution of $\Delta_{s}$ for energies of $2 \mathrm{eV}$ and $4 \mathrm{eV}$ on silicon wafer as a function of the incident angle.

Figure 3: Raw ellipsometry curves showing $\Delta$ as a function of temperature, measured for a $22 \mathrm{~nm}$ thin iPMMA film deposited on Piranha treated surface. (a) and (b) correspond to data recorded at $3.4 \mathrm{eV}$ and $2.2 \mathrm{eV}$, respectively.

Figure 4. Schematic description the depth structure of the iPMMA film on a silicon wafer. The upper curve Fig. 4a) shows the evolution of $T \pm, T+$ for iPMMA thin film deposited on activated silicon wafer as a function of the thickness. The lower curve Fig 4b) shows the evolution of T士 for an iPMMA film on a HF treated silicon wafer.

Figure 5. a) Tapping AFM image of $i-P M M A$ spin-coated on piranha treated silicon wafers (scan size is $843 \mathrm{~nm} \times 843 \mathrm{~nm}$ ) and b) corresponding cross section analysis showing the height $(Z)$ and lateral dimension $(D)$ of isolated globules.

Figure 6. Raw ellipsometry curves showing $\Delta$ as a function of temperature, measured individual iPMMA chains deposited on Piranha treated surface. 
Figure 1

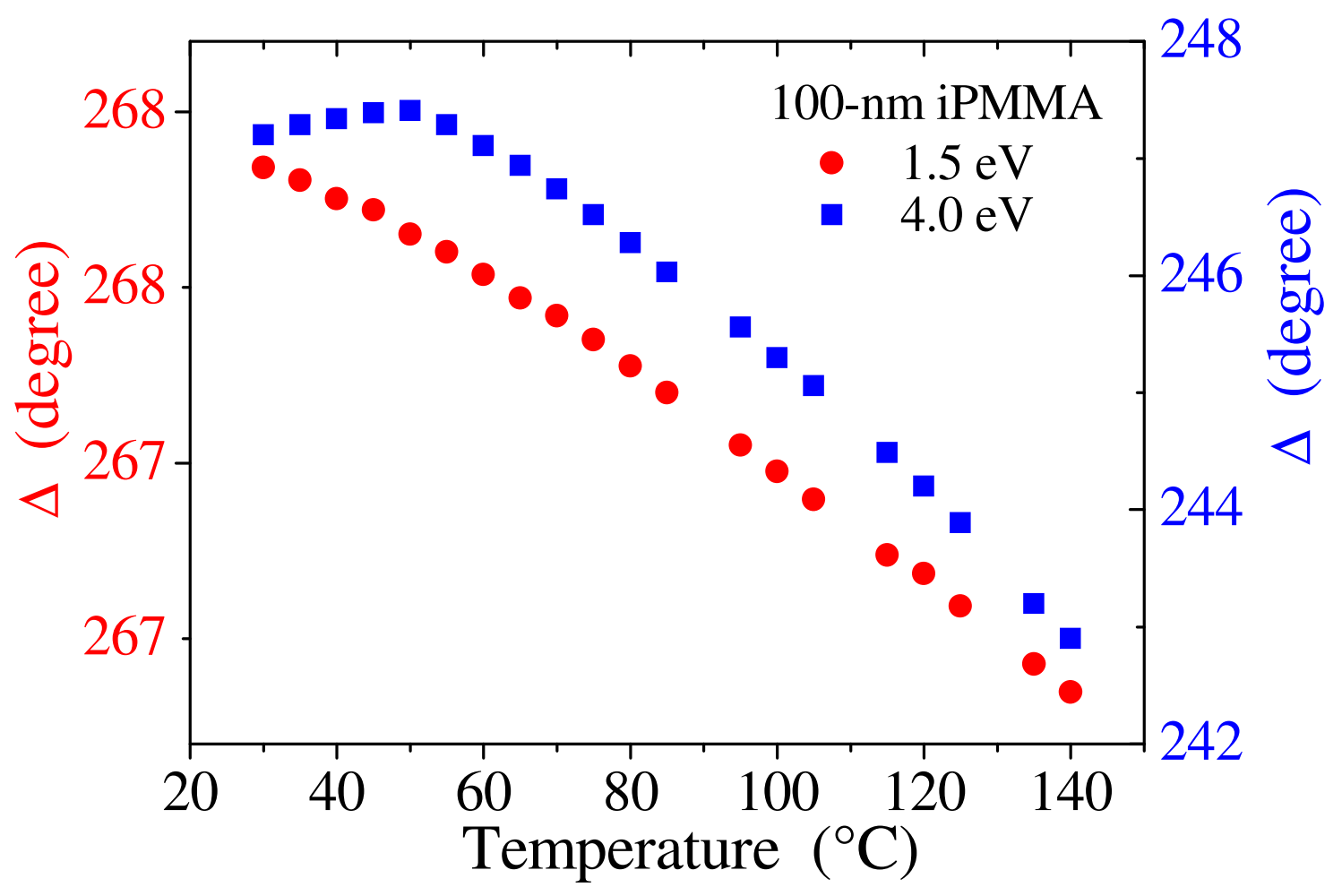


Figure 2

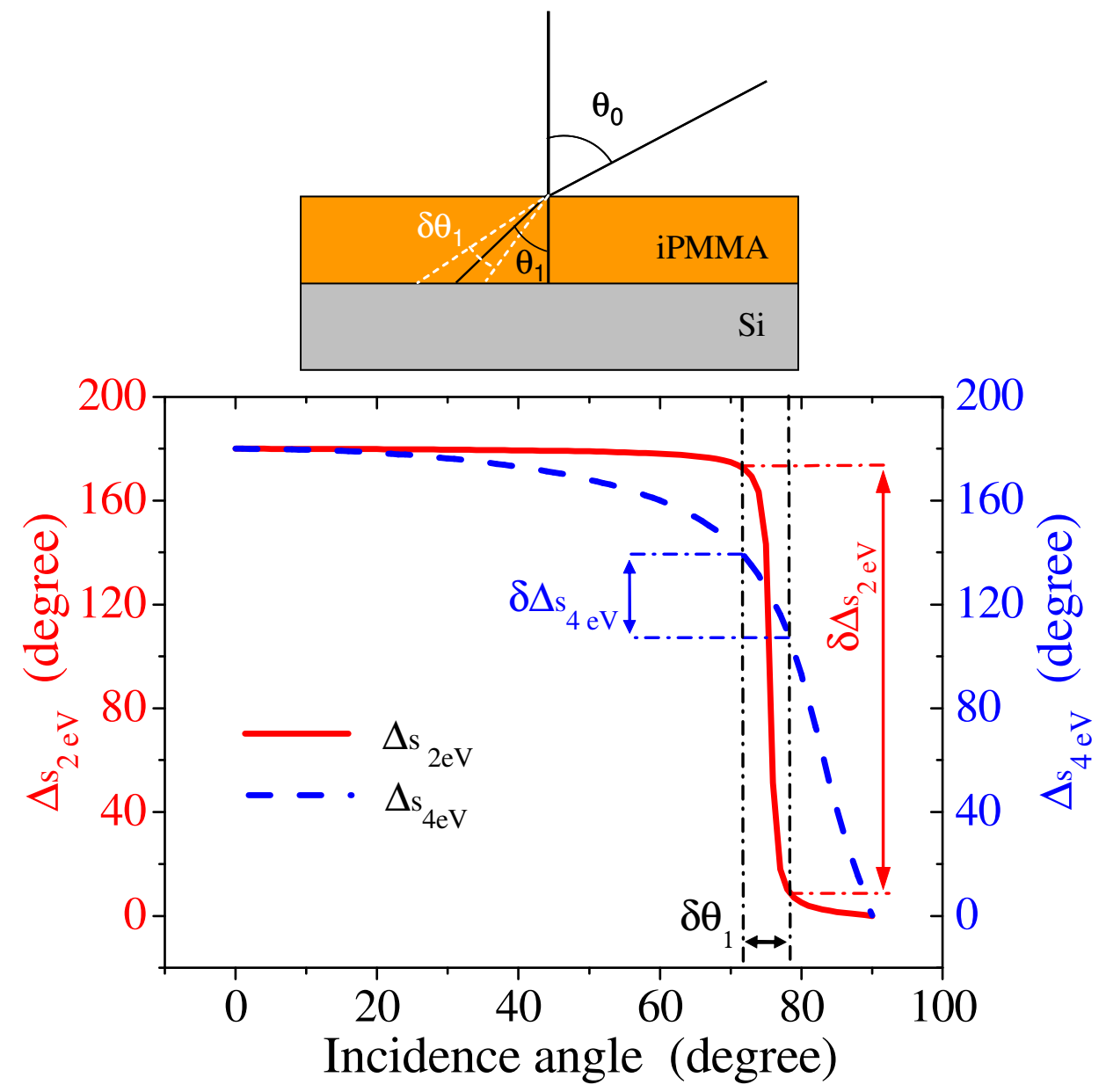


Figure 3
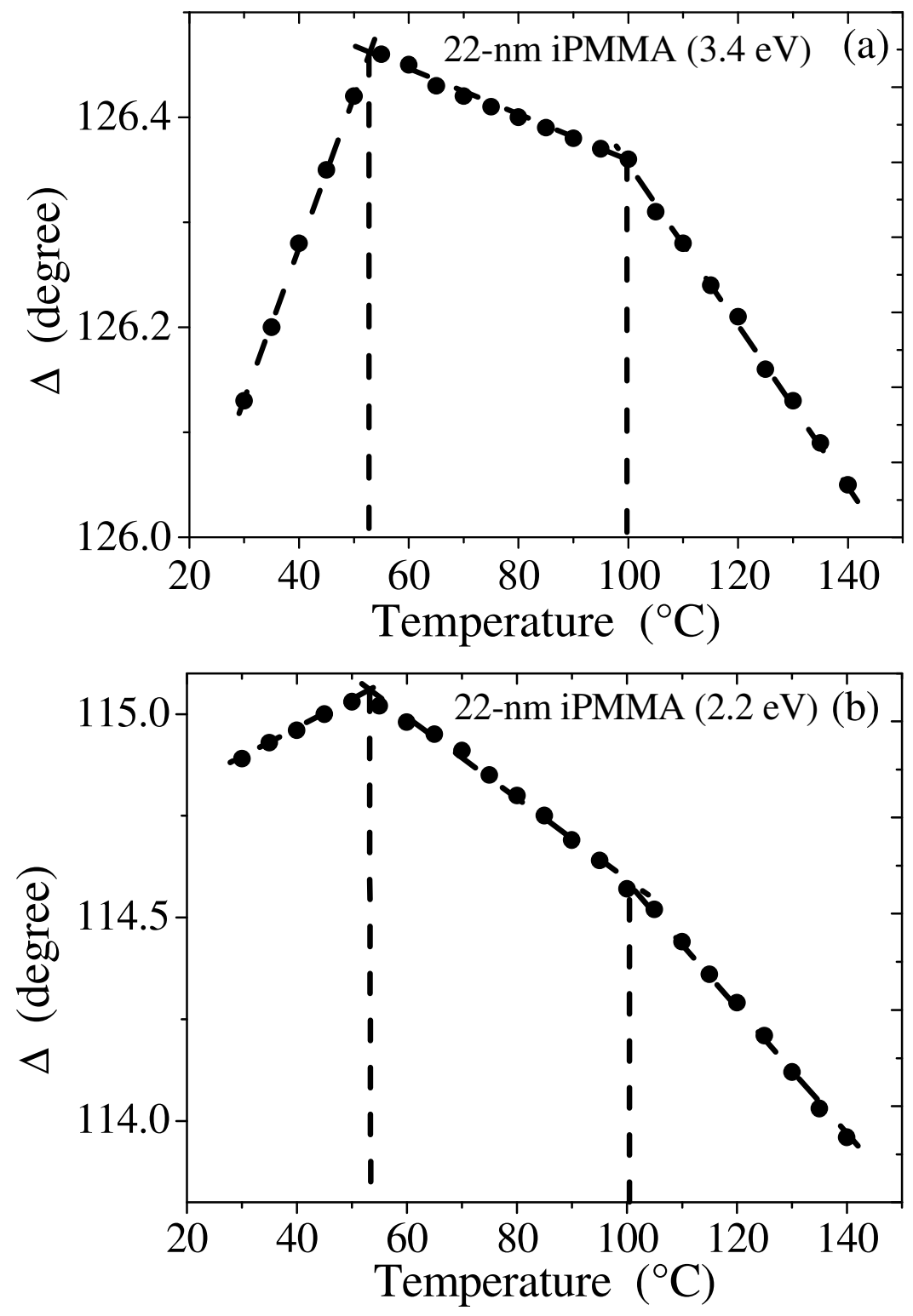
Figure 4

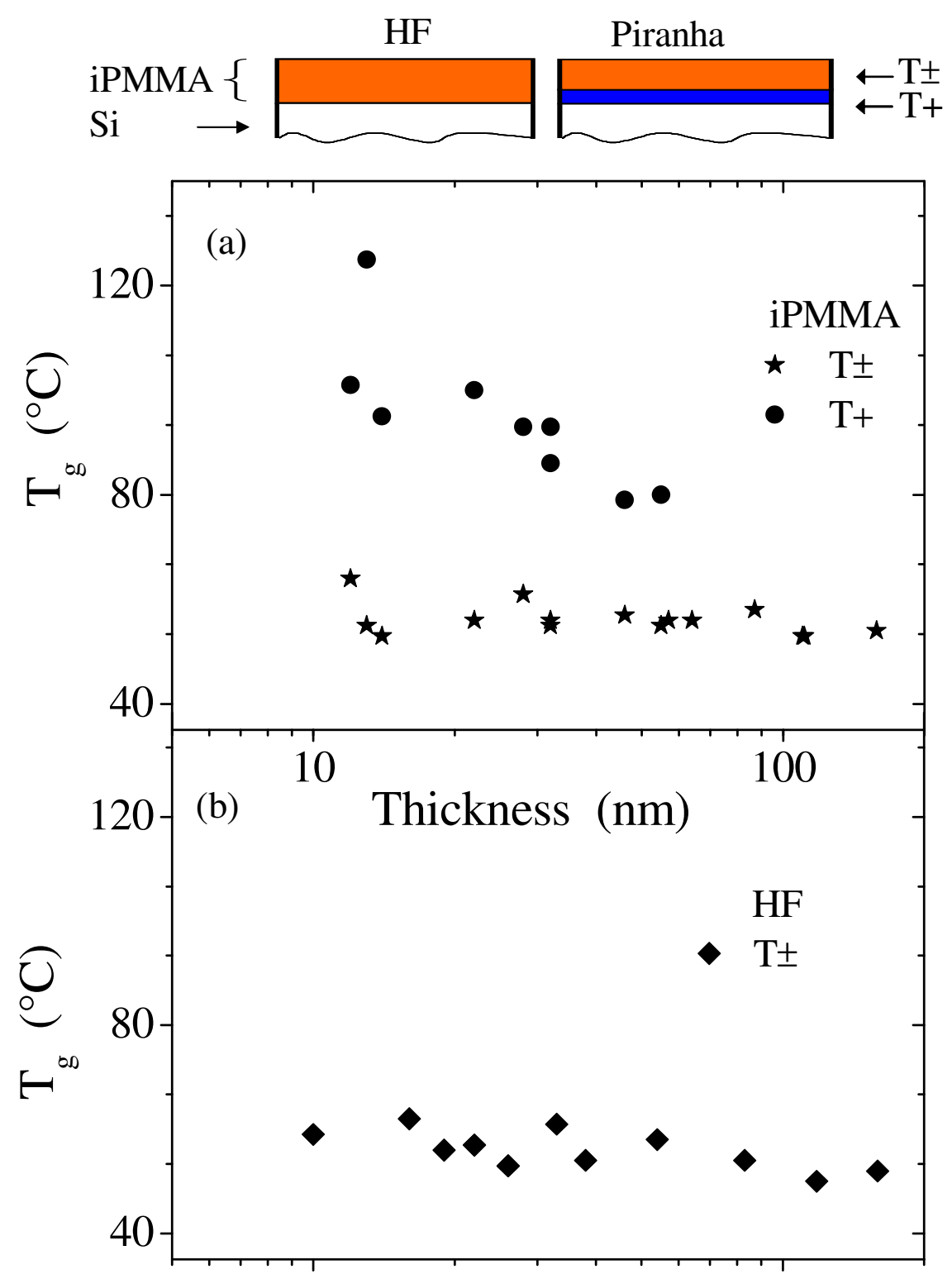


Figure 5

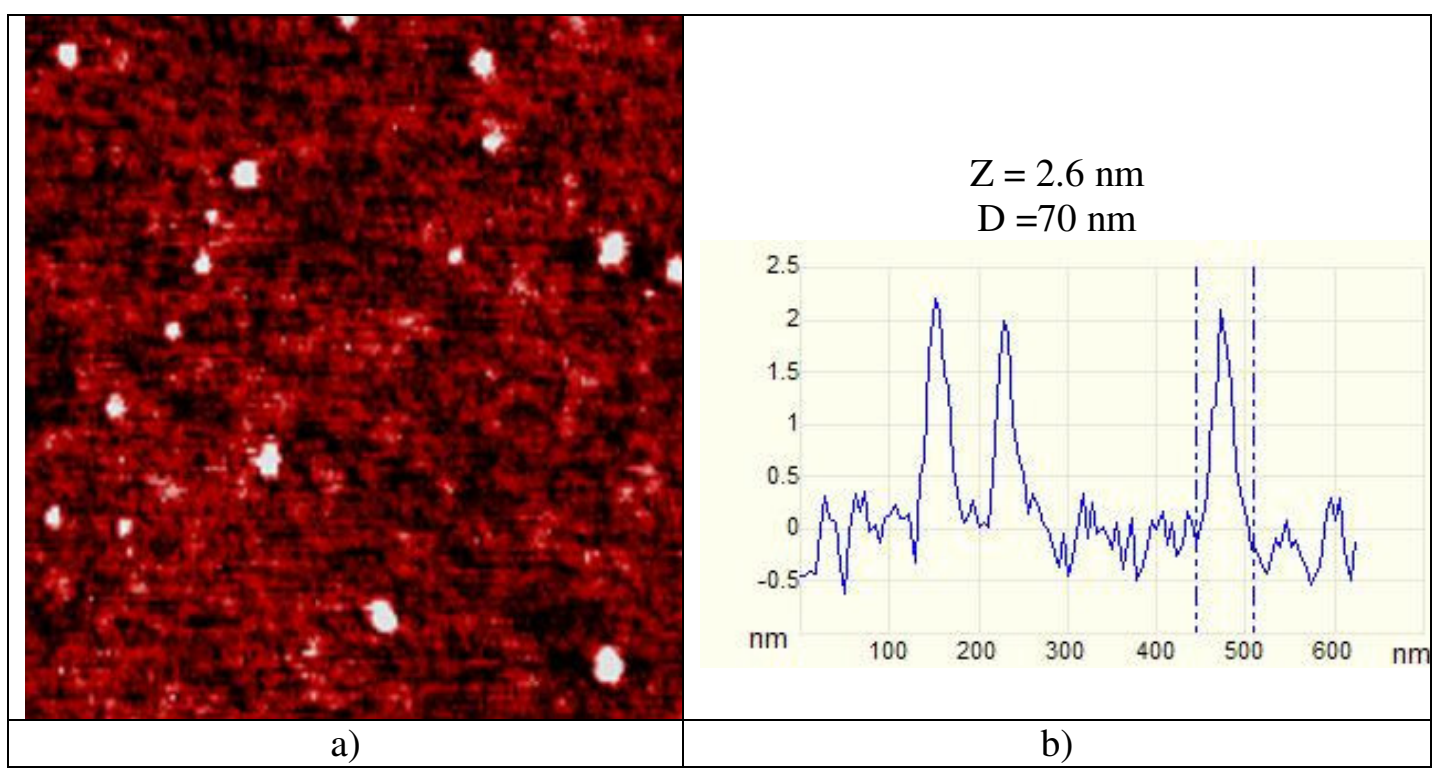


Figure 6

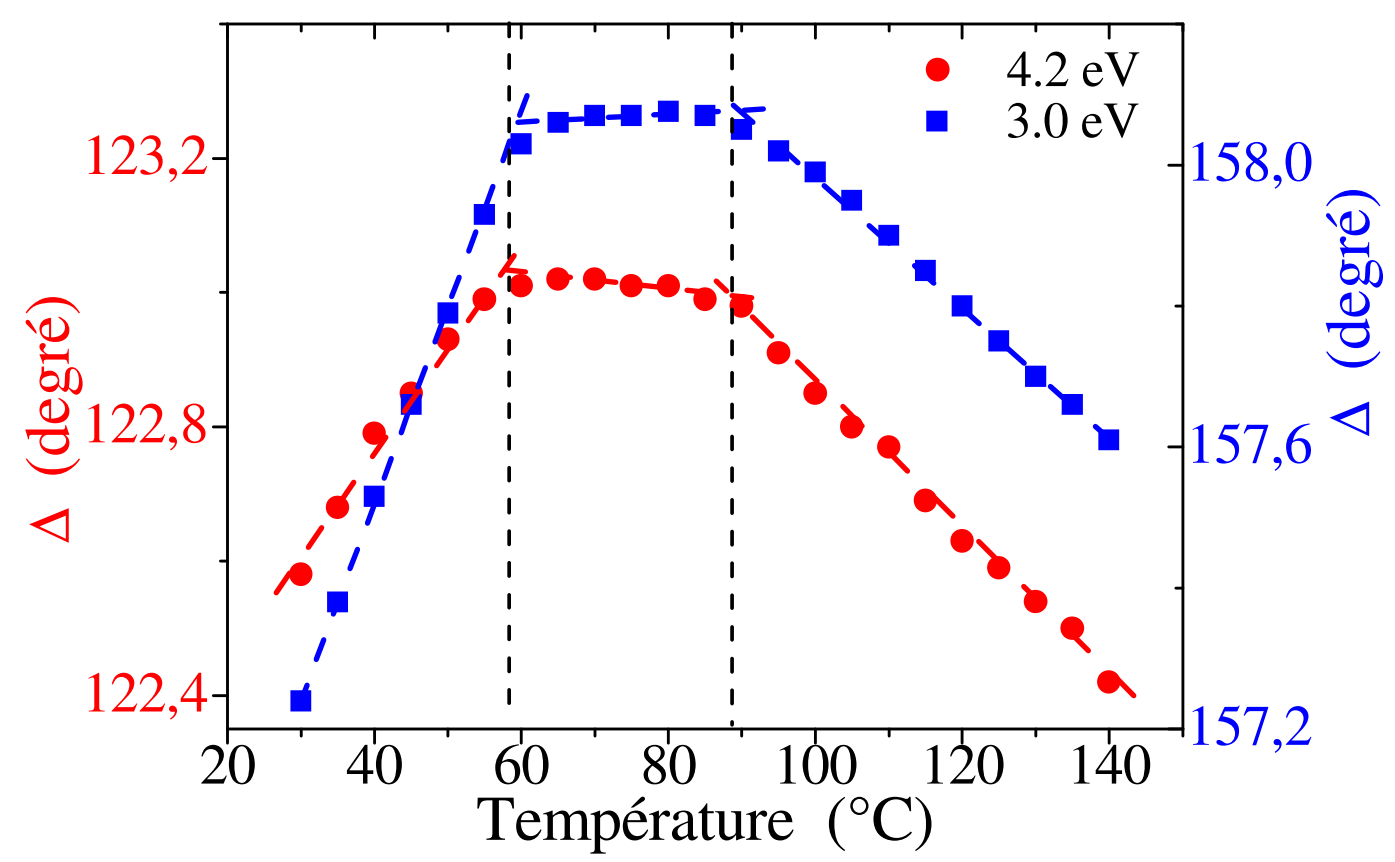

